Proceedings

\title{
Current Progress of Electrospun Nanocarriers for Drug Delivery Applications
}

\author{
Mina Zare and Seeram Ramakrishna \\ Center for Nanofibers \& Nanotechnology, National University of Singapore \\ * Correspondence: orresponding authors: seeram@nus.edu.sg , zare.mina@yahoo.com \\ Received: date; Accepted: date; Published: date
}

\begin{abstract}
Electrospinning is a powerful and cost-effective method that applies a strong electric field and polymer solution to fabricate versatile nanofiber using a wide array of raw materials for different biological applications. Electrospun nanofibers have developed as potential materials for the manufacturing of nanocarriers for therapeutic platforms due to controllable surface decoration, large surface areas, complex pore structure, good surface functionalization with high biocompatibility. The prominence of this technique is the possibility of merging low soluble drugs loaded in the nanofibers to enhance drug release and bioavailability. Incorporation of metal nanomaterials with electrocatalytic and/or plasmonic features into electrospun polymer nanofiber enhances thermodynamic and mechanical properties to obtain synergetic function and properties. This review comprehensively discusses an overview of theory of electrospinning, progress and concerns, and challenges currently face in fabricating efficient and effective drug delivery systems. Additionally, the drug-loaded into electrospun nanocarriers for drug delivery applications and insights into future prospects were explained.
\end{abstract}

Keywords: Electrospun; drug delivery; nanofiber; nanocarrier; surface functionalization; encapsulation

\section{General overview}

Nanotechnology is a promising technique that dramatically developed with an impressive impact in the healthcare industry for prevention, diagnosis, and treatment [1]. Drug delivery using nanocarrier is one of the many areas in healthcare in which nanotechnology is advancing [2]. Drug delivery systems are nanocarriers that can load with molecules that can act as a carrier of specific substances to be applied in the pharmaceutical industry [3]. Nanocarriers can enable a novel class of therapeutics, minimize the side effect of available drugs and improve the therapeutic efficacy, transfer bioactive agents into target zone, and encourage the development of research on biologically active new molecular entities for pharmaceutical applications [2,4,5]. Liposome [6], nanoemulsions [7,8], Pickering emulsions [9], micelles [10,11], dendrimers [12], and polymeric nanoparticles reported as nanocarriers in drug delivery systems [4]. There are challenges, and concerns in fabricating efficient drug delivery system for enhancement of biomedical investigation. The main challenges in drug delivery system is target delivery, solubility and degradation rate of drugs $[13,14]$.

Spinning technique forms a group of top-down approaches including electrospinning [15], microfluidic spinning [16,17], centrifugal spinning [18,19], and solution blow spinning [20,21], which produce polymer-based 1D nanoscale objects for biomedical applications. Electrospinning approaches developed remarkably in drug delivery application in order to increase fiber productivity, versatility and controlled morphology of the deposited nanofibers include coaxial electrospinning, melt electrospinning, solution electrospinning, multi-jet electrospinning, near-field electrospinning, and needless electrospinning $[4,15,22]$. Electrospinning techniques are cost-effective, controllable process, reproduceable, simple and versatile for manufacturing of non-woven fiber in Proceedings 2020, 4, $\mathrm{x}$; doi: FOR PEER REVIEW www.mdpi.com/journal/proceedings 
micro to nano range $(50 \mathrm{~nm}-500 \mu \mathrm{m})$ with diverse morphology (e.g. patterned, core shell, hollow random, janus, and aligned) for numerous purposes such as drug delivery, therapy techniques, biomaterials, tissue engineering, regenerative medicine, biosensing, surgical masks, and disease modeling [22,23]. Nanofibers with great criteria including large surface area-to volume ratio, low hinderance for mass transfer, high interfiber porosity, adjustable morphology, flexible handling and appropriate mechanical properties are suitable for therapeutic patches, nanocarriers in drug delivery and porous fibrous mats for biomedical applications. Fig. 1 illustrates the properties and the biophysiochemical features of nanocarriers for drug delivery applications.

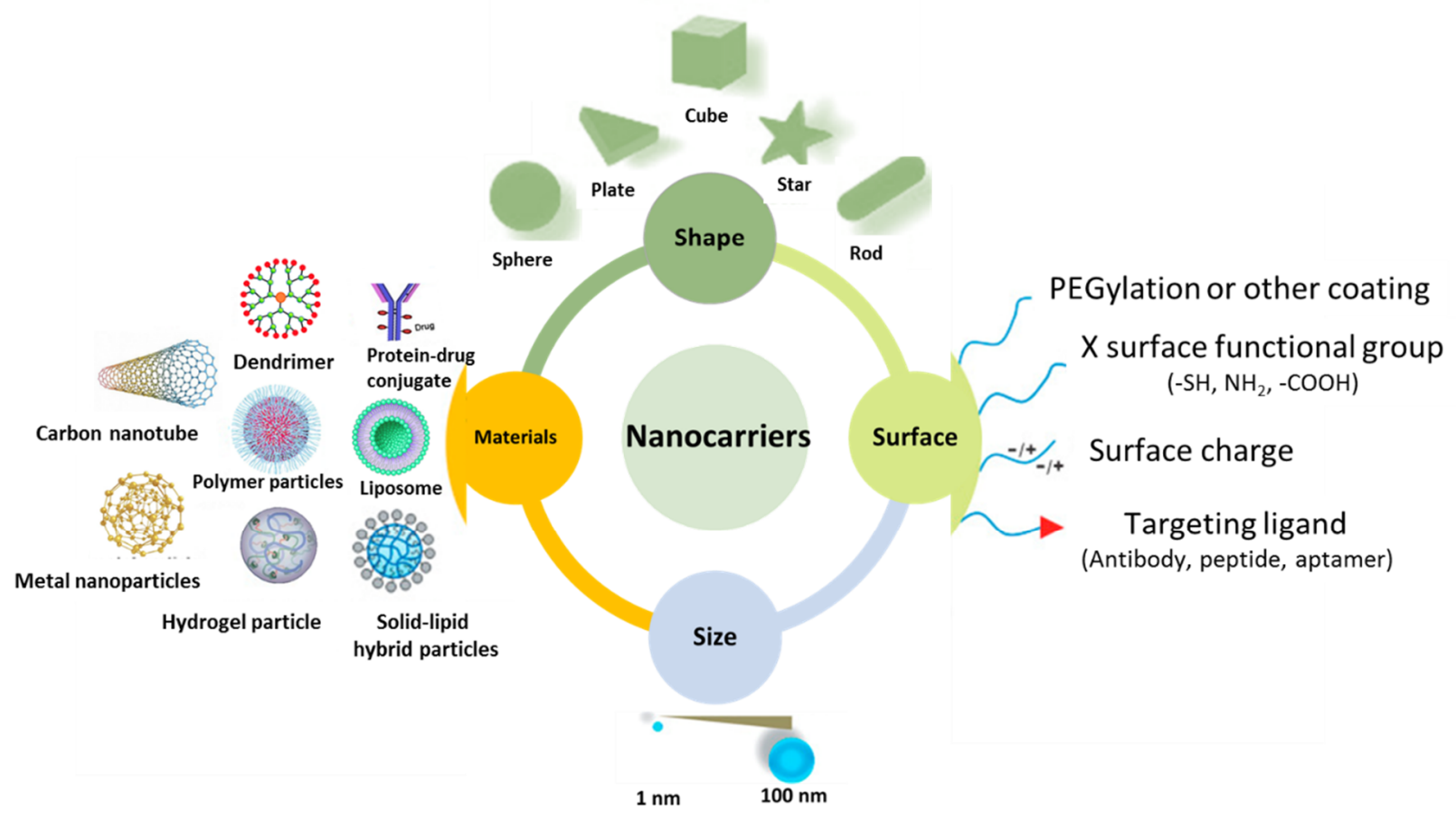

Figure 1. The nanocarriers for drug delivery approach and the biophysiochemical properties. Many factors are involving in the therapeutic potential of nanocarriers in drug delivery applications including size, shape, materials, and surface chemistry of nanomaterials. The size of nanomaterials can be in the range of 1 to $100 \mathrm{~nm}$ and with structures such as dendrimers, liposomes, polymer, hydrogels, metal nanoparticles. The surface functional group, coating, surface charge, and targeting ligand impact on the properties of drug delivery.

Recently, noticeable number of biocompatible nanofibers scaffolds fabricated using biodegradable synthetic polymers (poly ( $\varepsilon$-caprolactone) (PLC), poly lactic-co-glycolic acid (PLGA) , poly lactic acid (PLA), Polyethylene glycol (PEG), poly butylcyanoacrylate (PBCA)) via electrospun approaches $[24,25]$. The most investigated stimuli-responsive behaviour polymers are poly $(\mathrm{N}-$ Isopropylacrylamide) (pNIPAM) and poly(4-vinylpyridine) with thermo and $p H$-responsive polymers, respectively [26-28]. Several process factors including feeding rate $(0.01-1 \mathrm{~mL} \mathrm{~min}-1)$, polymer concentration and composition, solvent volatility, elasticity, viscosity, conductivity, the distance between the metal collector and the injector $(5-20 \mathrm{~cm})$, electric field strength, applied voltage $(5-35 \mathrm{kV})$, and external factors such as humidity and temperature affect the fiber diameter in electrospinning approaches $[22,28]$.

This review we represented an overview on theory of electrospinning, achievements and concerns and challenges currently face in fabricating efficient drug delivery system. Additionally, the drug-loaded into electrospun nanocarriers for drug delivery applications and opportunities, and insights into future prospects are explained.

\section{Drug delivery challenges}


The main challenges for effective drug delivery are solubility, degradability, and target delivery of the drugs (Fig. 2). Biopharmaceutical system classification (BCS) categorized drugs into four classes (I, II, III, and IV) based on permeability and solubility of active pharmaceutical ingredients. The definition of permeability is different in-vitro and in-vivo assesses, and a permeable drug is one associated with $90 \%$ absorption as evaluated by urinary extraction data, or $90 \%$ oral bioavailability. Solubility defined as the maximum concentration of drug in solution when a solid drug/solvent mixture has been allowed to reach equilibrium. Permeability refers to the ability of a drug to achieve the latter is known as its permeability. Dissolution rate is a kinetic term, and details how quickly the drug dissolves into solution. Class I drugs dissolve easily in the formulation and permeable, therefore can be used relatively into drugs ( $35 \%$ of drugs). Class II drugs possess low solubility in the formulation and easy permeability $(\sim 30 \%)$. Class III can be formulated into drugs easily but they are less soluble which needs permeation enhancer to allow them to pass to the systematic circulation $(\sim 25 \%)$. Class IV drugs are tremendously challenging to apply in the formulation of medicine to be permeable and soluble ( $10 \%)$. Table 1 demonstrates the permeability and solubility of BCS.

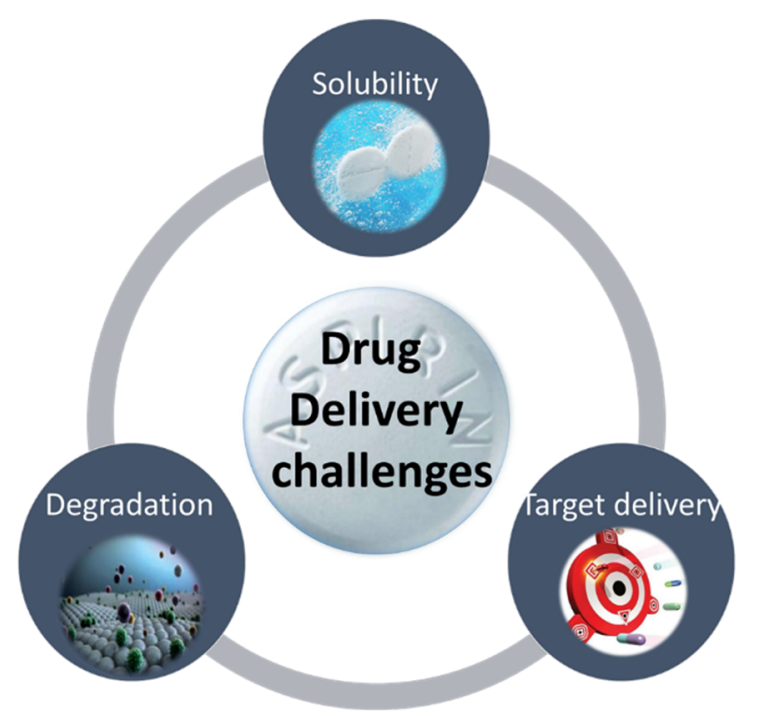

Figure 2. The main drug delivery challenges are solubility, degradation, and target delivery. By crystal modification, $\mathrm{pH}$ modification, size reduction, crystallization, solvent polarity adjustment, use of surfactant/ lipids, use of complexing agents, drug dispersions can solve the solubility problem to some extent. The degradation of drug carriers can be modified by chemical degradation techniques; oxidation, isomerization, hydrolysis, photolysis, and polymerization process, physical degradation; amorphous to crystalline transformation, and precipitation. Targeting drug delivery allow targeted deposition at the intended site, sustained release, safety, reduced dosing frequency, and patient convenience. There are two target delivery approaches include 1. Passive (Physiology-Based) Targeting 2. Active Targeting (2.1 Targeting Mediated by External Stimuli 2.2 Antibody-Directed Enzyme Prodrug Therapy 2.3 Targeting in Gene Therapy). 
Table 1. The Biopharmaceutical Classification System Class Solubility Permeability [29].

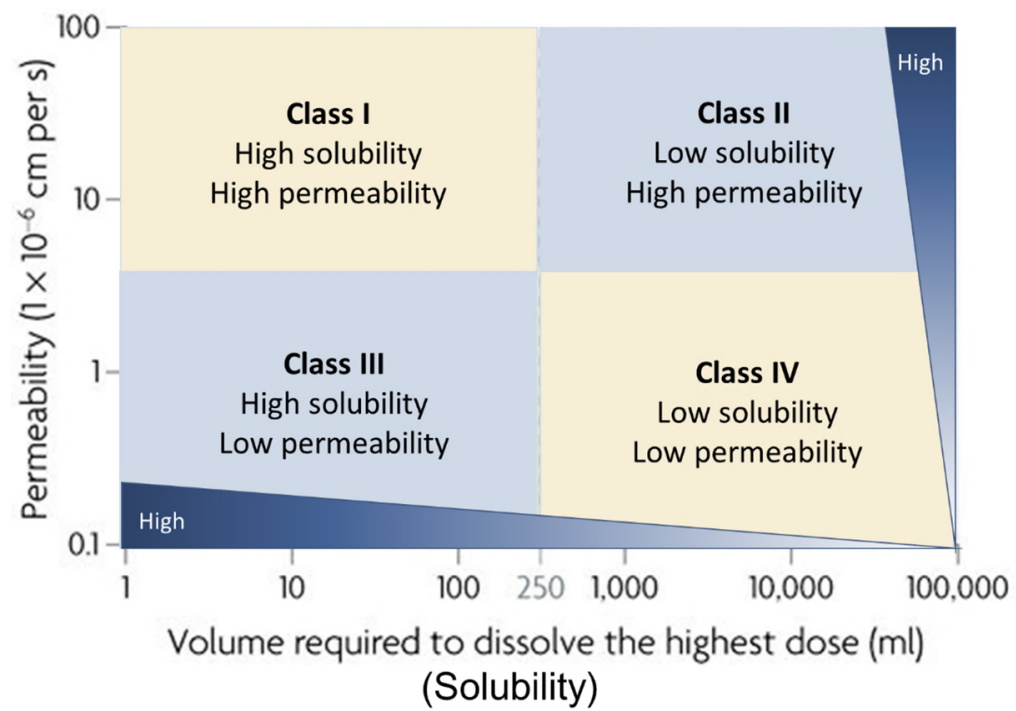

\subsection{Solubility}

After identifying the biological target, the main element for the successful formulation of dosage is to know the physicochemical features of the drugs. Solubility, stability, molecular weight, partition coefficient, and hygroscopicity of the drugs are important for effective drug formulation. The aqueous solubility of drugs is remarkably challenging for the formulation scientists, due to molecular property that possesses a vital role in-vivo a drug's bioavailability and distribution. The combination of solubility and permeability is demonstrated by the amount of passive drug penetration across a biological membrane. The foremost reason for many drug development failures is inadequate solubility of drugs [30-32].

There are several strategies to enhance the solubility of drugs including $p \mathrm{H}$ modification, crystal modification, size reduction, crystallization, solvent polarity adjustment, use of surfactant/ lipids, use of complexing agents, and drug dispersions. $p \mathrm{H}$ modification by salt formation is an effective strategy for enhancing the aqueous solubility of basic and acidic drugs for parenteral formulation [33,34]. Most of the compounds can crystalize into a number of stable, metastable, and unstable polymorphs. The transformation of an amorphous solid to a crystalline drug may lead to a marked decrease in the extent and rate of solubility [35-37]. The size reduction into the micro and nano dimension by topdown approaches such as micronization and nanosizing increase the kinetic solubility, by increase the large surface area and a concomitant increase in the rate of dissolution. controlling the morphology, size and amorphous-crystalline conversions are challenging in these methods [38-41]. Applying water-co-solvent systems relies on creating a solvent mixture to made solubilize hydrophobic drugs which resemble the polarity of the less soluble medicines. Solvents such as ethanol, glycerol, dimethyl sulfoxide, dimethylacetamide, and N-methyl-2-pyrolidone, and propylene-glycol have limitations in high concentration [42-44]. Surfactant solubilization fundamentally based on encapsulation of the hydrophobic part to develop either kinetically (e.g., liposomes) or thermodynamically (e.g., micelles) steady solution to assure sufficient dissolution of the solute [45-48]. The cyclic oligosaccharides (cyclodextrins) are composed of glucopyranose units with an inner hydrophobic surface and outer hydrophilic surface to form a central cavity and 'conelike' toroid structure. This morphology of cyclodextrin molecule embedded a hydrophobic drug molecule inside the hole and make an inclusion complex which is an effective way to enhance bioavailability and solubility of drugs [49,50]. The solid dispersion approach is an effective technique to solubilize hydrophobic compounds contain microcrystals in an inert crystal matrix-like urea or sugar. The crystalline dispersion causes a thermodynamically stable matrix. This method is more efficient than a solid dispersion system and dissolution [51,52]. 


\subsection{Degradation rate}

The complex nature of chemical compounds causes a problem in the decomposition and degradation of medicine. Decomposition can lead to the formation of toxic substances or reduce the efficacy of drugs. Degradation is including chemical and physical degradation. Chemical degradation is through oxidation, isomerization, hydrolysis, photolysis, and polymerization process and physical degradation comprises processes such as amorphous to crystalline transformation and precipitation. Modification of molecular structure ionic strength adjustment, and $p \mathrm{H}$ control of drug substances are formulation approaches to prevent degradation [53-55].

\subsection{Target drug delivery}

The target drug delivery technique is an important and powerful method that is desired for treating several medical conditions. This approach is an effective approach in cancer therapy, and in drugs with short half-lives lesser than 4 hours, because decreases the intensity of undesired sideeffects of medicine due to drug concentration fluctuations. Drug targeting improves the delivery of the drug to the specific tumor site and protect it from the extracellular environment [56,57]. Labeling of nanoparticles with biomolecules and receptors ease attachment to the target cell. The most targeting molecules are antibodies against the anti-epidermal growth factor receptor and epithelial growth factor [58,59]. Polymer nanoparticles, polymer/inorganic nanocomposite, inorganic nanoparticles with diverse structures and morphologies used for drug carriers' applications [57,60]. Target drug delivery cause safety and sustainable release, reduce dosing frequency, patient convenience, safety and allow targeted deposition at planned site. Target drug delivery includes active (physiology-based) and active targeting. Active targeting is mediated by external stimuli, antibody direct enzyme product therapy, and gene therapy. Cancer target therapy categorized based on the site of treatment such as Blood-Brain Barrier, skin, pulmonary, retina, Intracellular, and cologne [61].

\subsection{Spinning}

Electrospinning has been extensively acknowledged in recent years, due to its ability to rapidly fabricate nanofibers and nanoparticles for drug and therapeutic agent delivery, tissue engineering and regenerative medicine, wound dressing, biological sensing and filtration devices applications $[95,96]$. Electrospinning is a top-down technique for the synthesis of 1D nanomaterials using a wide range of feedstock such as sol-gel, polymer, melts, or suspensions. Moreover, the nanofibers can be loaded with nanoparticles, drugs or prodrugs, and chromophores [97,98]. Selection of proper spinning techniques is critical for a specific application. Spinning methods are physical solidification process, that limits the materials, structure, and types of fibers. The innovations of spinning method include electrospinning, microfluid spinning, centrifugal spinning, solution blow spinning, and electrospray as illustrates in Fig. 3. This review article is emphasizing on electrospinning techniques, which is only well-developed method for fabrication of uniform nanofibers and nanoparticles for diverse biomedical applications.

2.4.1. Drugs carrier in spinning technique
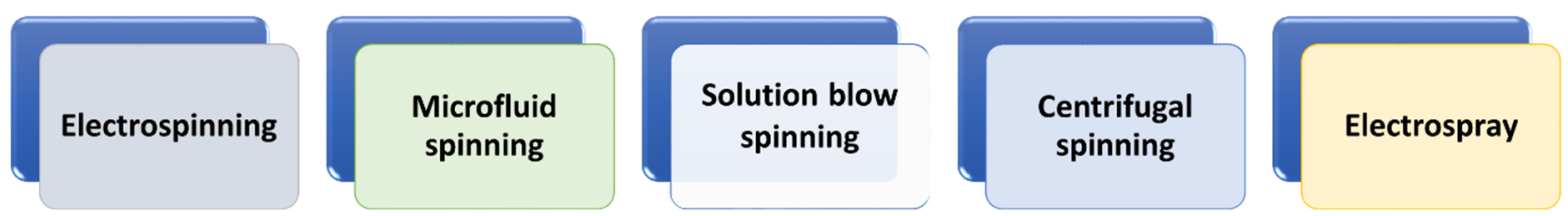

Figure 3. illustrates the current spinning methods. Electrospinning and electrospray techniques are electrodynamic atomization methods. Electrospray approach fabricates monodispersed, and fine aerosol of charged particles, while electrospinning prepares micro/nanofiber [98,99]. Microfluid 
spinning is a method for generation of complex nanostructure and allow the accurate manipulation of fluid within microscale channels, and allow for fast prototyping and bulk production of nozzles [100]. The centrifugal spinning technique applies a high-temperature around 900-1000 C to maintaining liquid state and spinning heat rotation more than $3000 \mathrm{rpm}$ [101]. Solution blow spinning technique is applying a gas-flow-focusing liquid, in low voltage to generate fiber using a volatile solvent and pressurized gas that flow around the polymer solution [102].

\subsection{Electrospinning as a drug incorporation technique}

William Gilbert in 1600 reported electrospinning technology by the movement of liquid and electrostatic attraction of liquid droplets using electric forces [105,106]. Electrospinning consists of four basic sections 1) injection/syringe pump, 2) spinneret and a nozzle/needle, 3) high voltage power supply 4) collector as shown in Fig 5. The polymer solution/melt is pumped out at a steady flow rate via spinneret to the nozzle which connected to the high voltage power supply and then fibers draw from the needle tip (Taylor cone) under the electrostatic forces and collect on the collector [107].

Several factors influence fiber morphology and production in the electrospinning process including solution properties (solution conductivity, viscosity, volatility, concentration, molecular structure, and molecular weight), environmental parameters (temperature and humidity), and electrospun variables (distance, voltage, flow rate, and collector). Collector possesses a significant impact on the arrangement and productivity of the collected film structure and nanofiber [106]. The variation in the electrospun setup to obtain the nanofiber for specific application leads to the design of different types of electrospinning. The primary incorporation of drugs into the polymer is the dispersion or dissolving of drugs in the solution polymer, and after that is the electrospinning approach [104,108-111]. There are several electrospinning methods for incorporation of drugs for drug delivery applications including solution electrospinning, emulsion electrospinning, surface modification electrospinning, side by side electrospinning (janus), multi jet electrospinning, multiaxial electrospinning, coaxial electrospinning, and blending electrospinning as shown in Fig. 5. The cross sectional of electrospinning nanofibers illustrated in Fig. 6. 


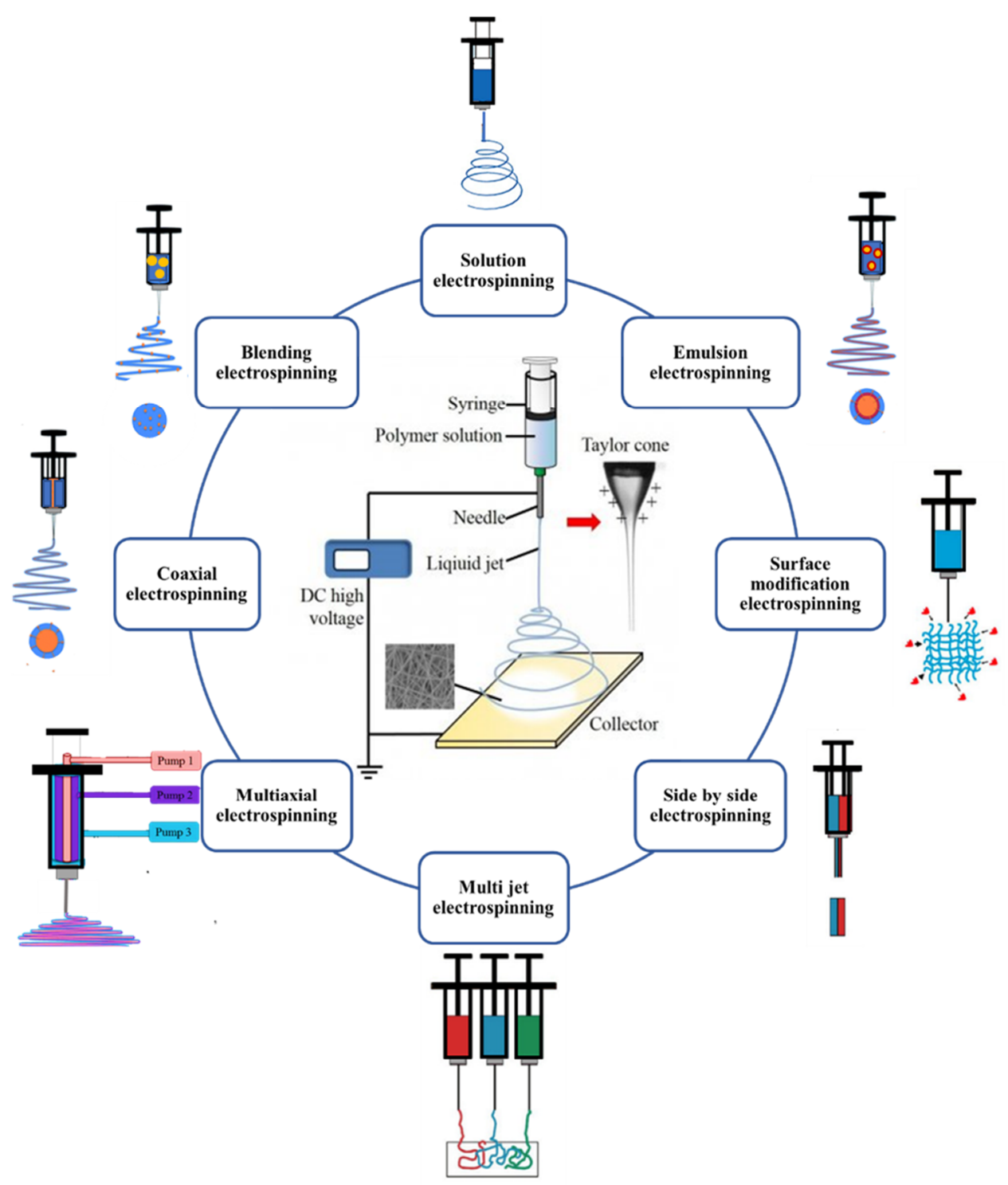

Figure 5. Schematic represents the different drug incorporation approach through electrospinning

Core shell
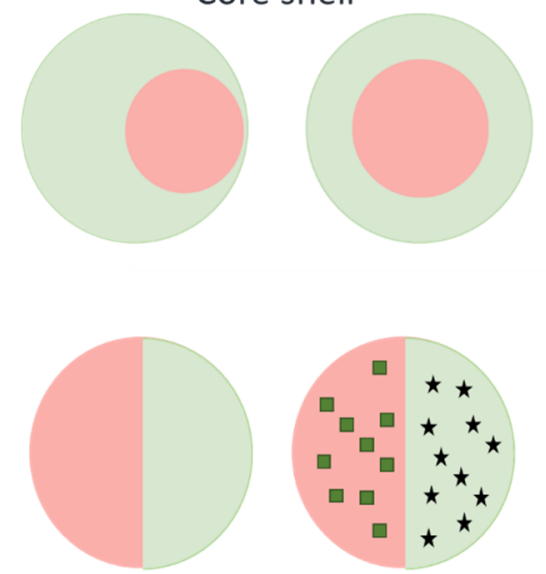

Side by side/ Janus

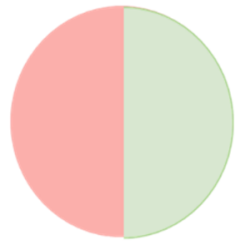

Hallow
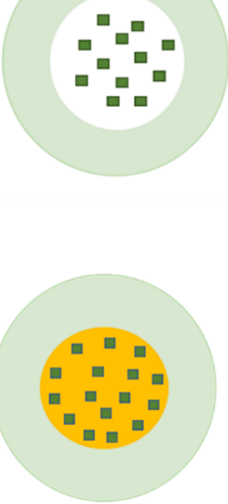

Coaxial

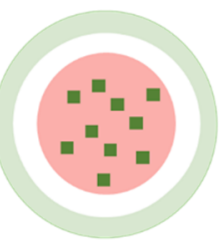

Triaxial
Single fiber
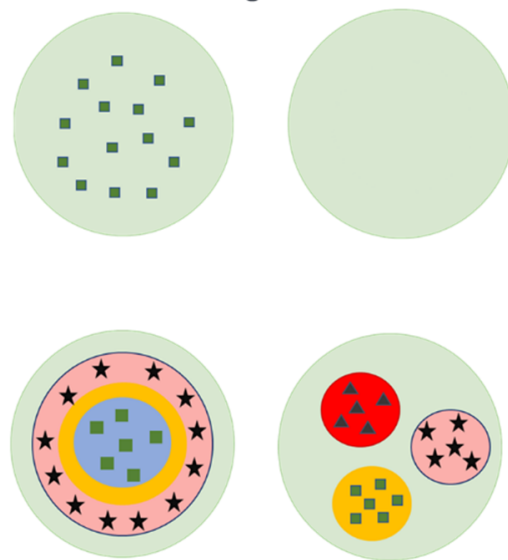

Multiaxial 
Figure 6. The cross-section of drug carrier fiber using electrospinning approach. In a single fiber, a drug is dissolved or dispersed in the fiber matrix. In the hollow fiber, the drug either dissolved in the fiber matrix or filled in the cavity of fiber. Core-shell fiber applied two different fiber solutions and the drug is covered in the core of the fiber. In the Janus fiber, two different bioactive agents (dissolved/ dispersed in the fiber) may be located side by side of the fiber. In the coaxial, the medicine is dispersed in the core and sheath around it. Triaxial and multiaxial fiber is composed of more fiber solutions using different bioactive agents. Island in the sea is a multiaxial technique in which all bioactive agents are embedded in the one fiber matrix.

Solution electrospinning system can generate nanofiber using different types of drugs, biological compounds, polysaccharides, and nucleic acid, protein, and thermosensitive polymers and materials. This technique needs a suitable solvent to dissolve drug into the polymer to form a uniform and homogenous spinning solution for the fabrication of nanofiber after evaporation of the solvent. The drug loading capacity in this method depends on the selection of solvents which is still challenging due to the drug and polymer are dissolved in the spinning solution [112].

Emulsion electrospinning fabricates core-shell nanofiber using emulsion for the encapsulation of growth factors, proteins, and drugs in to the inner core of nanocarrier. This method is effective for encapsulation of lipophilic drugs employing hydrophilic polymers to prevent apply of organic compounds. Also, the diluted polymer can be used without a negative impact on the quality of the nanocarrier. Three factors are involved in emulsion a) oil phase, b) water phase, and c) surfactants/emulsifiers, which impact on drug release. In the emulsion solution, a hydrophobic polymer dissolved in solvent (oil phase), while hydrophilic drugs dispersed in water (water phase). This approach is useful for the sustainable release of drugs, enhance bioavailability and effectiveness of encapsulated medicine after delivery and release, and to simplify the metabolism, proliferation, and differentiation of cells. Moreover, it reduces toxicity and frequency of drug administration $[113,114]$. The drawback of this technique is employing an emulsified solution for stabilizing the emulsion process which is not desirable and impacts the adhesion properties [104].

In surface modification electrospinning techniques a conductive surface can be chemically adjusted and developed with the aim of modifying the external feature of the device, by incorporating specific compounds to fortification the cover $[115,116]$. This method is useful to prevent rapid primary burst release and reduce the rate of immobilization of the biological molecules on a particular surface [103]. A recent study reveals dielectric barrier discharge oxygen plasma surface modified electrospun Bombyxmori silk/Amoxicillin hydrochloride trihydrate (AMOX)/polyvinyl alcohol (PVA) nanofibers for drug release applications significantly enhanced AMOX released rate. Besides, the obtained nanofiber shows good antimicrobial activity in gram-negative and gram-positive bacteria with less toxicity [117].

Side by side electrospinning (Janus), the challenge in this approach is to manipulate the working fluids with various features and confirm that the flowing rate is similar and ensure that these are drawn synchronously from the spinneret when parallel metal capillaries are using without separation under an electrical field. The spinneret design is critical to fabricate a template for prepare nanofiber and controlling the behavior of working fluids under an electrical field. This method is valuable in generating multi-functional nanofibers, also Janus structure allows direct contact of both compartments with their environment [118,119].

Multi-jet electrospinning approach exists in two forms including nozzle less and nozzles electrospinning. This technique is beneficial for large scale nanofiber fabrication and ameliorates productivity. Besides, this method affords the opportunity for the multicomponent polymer to gain blend nanofiber with adequate dispersibility and uniform thickness, using multi-polymer which unable to dissolve in a solvent with the same polarity. moreover, the fabricated nanofiber can deliver multiple drugs and multilayer polymer coating which permits sustainable drug release. The drawback of this approach is the alteration of the electric field because of the existence of another electrospinning jet in the environment, which can be solved by employing secondary electrodes or an auxiliary electrode of any polarity [78-80]. 
Coaxial electrospinning method is useful for the fabrication of core-shell drug-releasing nanofibers, core-sheath, hallow, and functional fibers loading with drugs using different solutions. This technique is a gentle process for the protection and encapsulation of DNA, RNA, proteins, drugs, and biopolymers with high susceptibility to destructive environment stimuli. Also, it can reduce the release rate of small drug molecules from the hydrophobic matrix. The merit of this approach including the high loading capacity of the diverse bioactive molecule, a slight harsh method which allows susceptible drugs to be delivered, possible for the generation of core-shell nanofibers from immiscible and miscible polymers, sustainable drug release for a longer time, and prevent the burst release, and it is feasible to generate nanofibers from unspinnable solution [108-110]. The great feature of this approach is the ability to alter the fiber thickness and modulate the release kinetics and the potential to sequester stimulants in various components. The disadvantage of this technique is the difficult removal of nanofibers from the collector [104].

Multiaxial electrospinning method employs more than three polymers solution are supplied into a Taylor cone via spinneret, which enables the generation of the more complex nanofiber. The drawback of this technique is the set of physical and chemical conditions. In this technique, the multiaxial nanofibers with different hydrophobicity and mechanical strength can generate. Due to the complexity of this technique, limited researches were carried out. Multiaxial fibers using multiple blends or polymers of synthetic or natural polymers have desirable mechanical, biological, and chemical features for target delivery through controlled arrangement and dimension. Also, different lipophilic, hydrophobic compounds such as drugs, inhibitors, DNA, growth factors, antibodies, and hormones can be incorporated into the heterostructure fiber through the spinning procedure. The drawback of this technique is the selection of solvents with proper boiling points [104,108,123,124].

Blending electrospinning technique ameliorates the equilibrium between physicochemical and mechanical properties of the drug-loaded in nanocarrier in a single phase. Besides, it effectively enhances the drug design formulation for the medicine to release from the polymer by amending the balance between polymer and drug in the blend solution. Also, blending electrospun provides a longterm drug release system by drug encapsulation and drug dispersion into the fiber $[125,126]$. The main weakness of this approach is clearance and denaturation of protein/drug substances with their severe burst release phenomenon, which reduce the lifetime hydrophilic drugs during encapsulation [114].

The three approaches to fabricate drugs in the spinning method include electrospray nanoparticles as drug carriers, electrospun nanofibers as drug carriers, and electrospray nanoparticles that incorporated into electrospun nanofibers as drug carries as display in Fig. 4. Table 2 shows the list of potential drug delivery applications of electrospun nanocarriers. In the electrospray method the bioactive polymeric solution is sprayed and generated drug monodispersed nanodroplets due to the separation of the polymer chains via the solvent system. The needle gauge diameter, distance between syringe and collector, voltage, flow rate, and conductive collector are factors are influence the precise incorporation of the drug. The advantages of this method are high encapsulation efficiency and scalable reproducibility and synthesis [103]. In electrospinning technique, the drug fabricates in the form of fibers. The operation parameters solution properties, and environmental conditions is impact on the final fiber features. Recently, the more advanced approach is developed by a combination of electrospun and electrospray techniques which incorporate hydrophobic or hydrophilic electrosprayed drug nanobeads in the electrospun fiber, while only a few studies are reported in this domain [104]. 


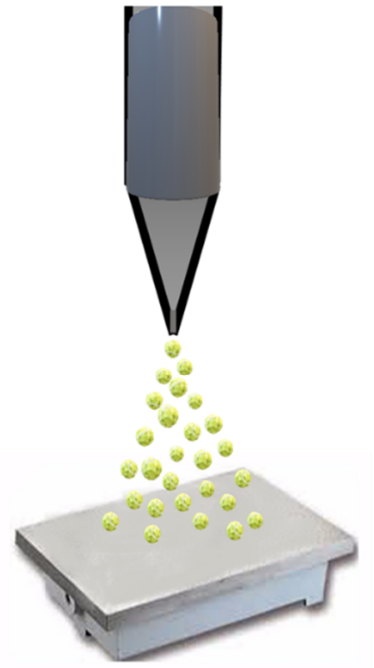

Electrospray Nanoparticles as drug carriers

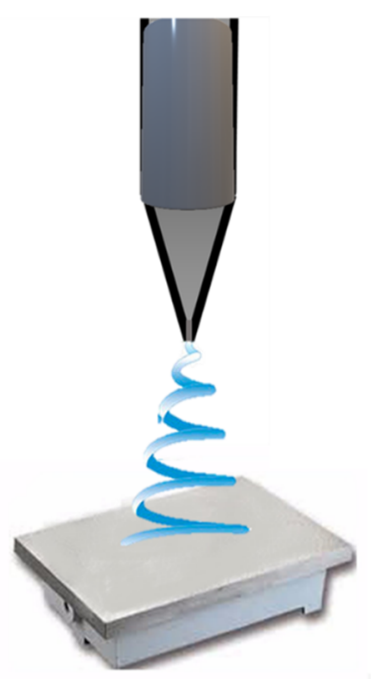

Electrospun nanofibers are drug carriers

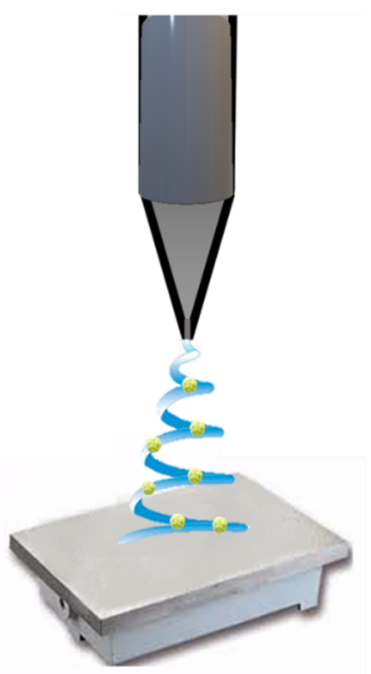

Electrosprayed Nanoparticles + electrospun nanofibers as drug carriers

Figure 4. The drug carriers in spinning approach.

Table 2. List of potential drug delivery applications of electrospun nanocarriers.

\begin{tabular}{|c|c|c|c|c|}
\hline Morphology & $\begin{array}{c}\text { Polymer } \\
\text { materials } \\
\text { system } \\
\end{array}$ & Drug types & Applications & Ref. \\
\hline Particles & PLGA & Doxorubicin & Antineoplastic drugs & [62] \\
\hline Fiber & PLA & Dichloroacetate (DCA) & Antineoplastic drugs & [63] \\
\hline Fiber & PCL, Gelatin & Doxorubicin (Dox) & Antineoplastic drugs & [64] \\
\hline Particles in fiber & PHB & $\begin{array}{l}\text { hydroxyapatite nanoparticle } \\
\text { (nHA }\end{array}$ & Antineoplastic drugs & [65] \\
\hline Fiber & PEG, PLGA & $\begin{array}{c}\text { 10-Hydroxycamptothecin } \\
\text { (HCPT)/hydrophilic tea } \\
\text { polyphenol (TP) }\end{array}$ & Antineoplastic drugs & [66] \\
\hline Particles & PLA & Curcumin & $\begin{array}{l}\text { Antineoplastic and } \\
\text { antimicrobial drugs }\end{array}$ & [67] \\
\hline Fiber & PLA & $\begin{array}{l}\text { Doxorubicin (Dox)/doxorubicin } \\
\text { hydrochloride (Dox-HCl) }\end{array}$ & Antineoplastic drugs & [68] \\
\hline Fiber & $\mathrm{PVP}, \mathrm{HB}$ & Artemisinin (ART) & Antineoplastic drugs & [69] \\
\hline Fiber & PCL & Paclitaxel & Antineoplastic drugs & [70] \\
\hline Particles in fiber & PLGA & $\mathrm{NaYF}_{4}: \mathrm{Eu}^{3+}$ & Antineoplastic drugs & [71] \\
\hline Particles & PLGA & Curcumin & Antineoplastic drugs & [72] \\
\hline Fiber & PS & $\begin{array}{c}\text { Biotin-BSA/streptavidin- } \\
\text { biotin/biotinylated anti-EpCAM }\end{array}$ & Antineoplastic drugs & [73] \\
\hline Fiber & PLA, PEO & Rapamycin & Antineoplastic drugs & [74] \\
\hline Particles & PLGA-PBA & methotrexate & Antineoplastic drugs & {$[75]$} \\
\hline Particles & PLA & Berberine & Antineoplastic drugs & [76] \\
\hline Fiber & PCL & Ibuprofen or carvedilol & Anti-inflammatory painkillers & {$[77]$} \\
\hline Fiber & PCL & Naproxen (NAP) & Anti-inflammatory painkillers & [78] \\
\hline Fiber & EC, zein & Indomethacin & Anti-inflammatory painkillers & [79] \\
\hline Fiber & PCL, gelatin & Ketoprofen & Anti-inflammatory painkillers & [80] \\
\hline Fiber & CA, PVP & Amoxicillin & Antimicrobial & {$[81]$} \\
\hline Fiber & PEG, PCL & Curcumin/doxorubicin & Antimicrobial & {$[82]$} \\
\hline Fiber & PCL & Metronidazole/ciprofloxacin & Antimicrobial & [83] \\
\hline Fiber & PCL & Gentamicin/Ag & Antimicrobial & [84] \\
\hline Fiber & PCL, chitosan & Ciprofloxacin & Antimicrobial & {$[85]$} \\
\hline
\end{tabular}




\begin{tabular}{ccccc}
\hline Fiber & $\begin{array}{c}\text { PVP, PCL, } \\
\text { cellulose acetate }\end{array}$ & Nisin & Antimicrobial & {$[86]$} \\
\hline Fiber & PCNU & Antimicrobial oligomer (AO) & Antimicrobial & {$[87]$} \\
\hline Fiber & $\begin{array}{c}\text { Poly(methyl } \\
\text { vinyl ether-alt- } \\
\text { maleic ethyl } \\
\text { monoester) }\end{array}$ & $\begin{array}{c}\text { Salicylic acid/methyl salicylate } \\
\text { capsaicin }\end{array}$ & Psoriatic lesions treatment & {$[88]$} \\
\hline Fiber & PLGA & Growth factors & Regenerative medicine & {$[89]$} \\
\hline Fiber & Chitosan, PEO & Insulin & Transbuccal insulin delivery & {$[90]$} \\
\hline Fiber & PVP & Carvedilol & Buccal delivery of Carvediol & {$[91]$} \\
\hline Particles & $\begin{array}{c}\text { triglyceride } \\
\text { tristearin }\end{array}$ & $\begin{array}{c}\text { Superparamagnetic iron oxide } \\
\text { nanoparticles and fluorophore }\end{array}$ & Theranostic agent & {$[92]$} \\
\hline Particles & Lactose & Dry powder inhaler & Pulmonary drug delivery & {$[93]$} \\
\hline Particles & Alginate & Silica supraparticles & Long term drug delivery & {$[94]$} \\
\hline
\end{tabular}

\section{Conclusions, Challenges, and Future Perspectives}

In conclusion, it is clear that the electrospinning method by the generation of desired nanofibers and nanoparticles possesses excellent potential in pharmaceutical applications. However, optimization of the different factors is crucial to generate nanocarriers with the desired function and morphology for drug delivery application. Also, the electrospinning approach is an effective strategy for sustainable drug release, target delivery, and encapsulation of drugs. Moreover, there are drawbacks to this system for the commercialization of nanocarriers for drug delivery. Therefore, further studies, standardization, and understanding of public health concern are required to develop marketable products.

Although, the most studies have been restricted to clinical translation and in-vitro proofs ofconcept of such approaches, however the significant developments in on-demand externally triggered nanocarrier-based drug release systems that needs further advances. The main challenges are related to the biological response, chemical complexity, and predictability of externally triggered release carriers in in-vivo physiological environment. Besides, the drug delivery systems schemes using nonbiodegradable materials may hinder the drug delivery applications in biomedical field. In this aspect, more studies are still essential to address these concerns.

In summary this review explored the challenges in drug delivery and the electrospinning emerging trends for the fabrication of nanofiber as a nanocarrier for drug delivery application. We explained the electrospinning system and each compartment. Also, the drug incorporation techniques into fiber using the electrospinning method for enhancement of bioavailability of the poorly water-soluble drugs and dissolution rate of drug are discussed.

Author Contributions: Mina Zare collected data for the review article contributed substantially to the discussion of the content and wrote, reviewed, and edited the manuscript before submission. Seeram Ramakrishna approved the final version to be published and supervised the work. The authors contributed to the finalization of the manuscript.

Competing Interests: The authors declare no competing interests.

Funding: The authors received no specific funding for this work.

Notes: The authors declare no competing financial interest.

\section{References}

1. Mei, L.; Wang, Y.; Tong, A.; Guo, G. Facile electrospinning of an efficient drug delivery system. Expert Opin. Drug Deliv. 2016, 13, 741-753.

2. Shi, J.; Votruba, A.R.; Farokhzad, O.C.; Langer, R. Nanotechnology in drug delivery and tissue engineering: From discovery to applications. Nano Lett. 2010, 10, 3223-3230.

3. Contreras-Cáceres, R.; Cabeza, L.; Perazzoli, G.; Díaz, A.; López-Romero, J.M.; Melguizo, C.; Prados, J. Electrospun Nanofibers: Recent Applications in Drug Delivery and Cancer Therapy. Nanomaterials 2019, 9, 656. 
4. Contreras-Cáceres, R.; Cabeza, L.; Perazzoli, G.; Díaz, A.; López-Romero, J.M.; Melguizo, C.; Prados, J. Electrospun nanofibers: Recent applications in drug delivery and cancer therapy. Nanomaterials 2019, 9.

5. Mediaswanti, K. Influence of Physicochemical Aspects of Substratum Nanosurface on Bacterial Attachment for Bone Implant Applications. J. Nanotechnol. 2016, 2016.

6. Mickova, A.; Buzgo, M.; Benada, O.; Rampichova, M.; Fisar, Z.; Filova, E.; Tesarova, M.; Lukas, D.; Amler, E. Core/shell nanofibers with embedded liposomes as a drug delivery system. Biomacromolecules 2012, 13, 952-962.

7. Alcalá-Alcalá, S.; Benítez-Cardoza, C.G.; Lima-Muñoz, E.J.; Piñón-Segundo, E.; Quintanar-Guerrero, D. Evaluation of a combined drug-delivery system for proteins assembled with polymeric nanoparticles and porous microspheres; Characterization and protein integrity studies. Int. J. Pharm. 2015, 489, 139-147.

8. Soppimath, K.S.; Aminabhavi, T.M.; Kulkarni, A.R.; Rudzinski, W.E. Biodegradable polymeric nanoparticles as drug delivery devices. J. Control. Release 2001, 70, 1-20.

9. Chevalier, Y.; Bolzinger, M.A. Emulsions stabilized with solid nanoparticles: Pickering emulsions. Colloids Surfaces A Physicochem. Eng. Asp. 2013, 439, 23-34.

10. Soleymani Abyaneh, H.; Vakili, M.R.; Zhang, F.; Choi, P.; Lavasanifar, A. Rational design of block copolymer micelles to control burst drug release at a nanoscale dimension. Acta Biomater. 2015, 24, 127-139.

11. Kataoka, K.; Harada, A.; Nagasaki, Y. Block copolymer micelles for drug delivery: Design, characterization and biological significance. Adv. Drug Deliv. Rev. 2001, 47, 113-131.

12. Zheng, Y.; Li, S.; Weng, Z.; Gao, C. Hyperbranched polymers: advances from synthesis to applications. Chem. Soc. Rev. 2015, 44, 4091-4130.

13. Li, C.; Wang, J.; Wang, Y.; Gao, H.; Wei, G.; Huang, Y.; Yu, H.; Gan, Y.; Wang, Y.; Mei, L.; et al. Recent progress in drug delivery. Acta Pharm. Sin. B 2019, 9, 1145-1162.

14. Gareth R. Williams, Bahijja T. Raimi-Abraham, C.J.L.- Nanofibres in Drug Delivery; UCL Press, 2018; ISBN 9781787350182.

15. Ibrahim, H.M.; Klingner, A. A review on electrospun polymeric nanofibers: Production parameters and potential applications. Polym. Test. 2020, 90.

16. Jun, Y.; Kang, E.; Chae, S.; Lee, S.H. Microfluidic spinning of micro- and nano-scale fibers for tissue engineering. Lab Chip 2014, 14, 2145-2160.

17. Du, X.; Li, Q.; Wu, G.; Chen, S. Multifunctional Micro/Nanoscale Fibers Based on Microfluidic Spinning Technology. Adv. Mater. 2019, 31, 1903733.

18. Badrossamay, M.R.; Mcllwee, H.A.; Goss, J.A.; Parker, K.K. Nanofiber assembly by rotary jet-spinning. Nano Lett. 2010, 10, 2257-2261.

19. Mamidi, N.; Zuníga, A.E.; Villela-Castrejón, J. Engineering and evaluation of forcespun functionalized carbon nano-onions reinforced poly ( $\varepsilon$-caprolactone) composite nanofibers for $\mathrm{pH}$-responsive drug release. Mater. Sci. Eng. C 2020, 112, 110928.

20. Medeiros, E.S.; Glenn, G.M.; Klamczynski, A.P.; Orts, W.J.; Mattoso, L.H.C. Solution blow spinning: A new method to produce micro- and nanofibers from polymer solutions. J. Appl. Polym. Sci. 2009, 113, 2322-2330.

21. Daristotle, J.L.; Behrens, A.M.; Sandler, A.D.; Kofinas, P. A Review of the Fundamental Principles and Applications of Solution Blow Spinning. ACS Appl. Mater. Interfaces 2016, 8, 34951-34963.

22. dos Santos, D.M.; Correa, D.S.; Medeiros, E.S.; Oliveira, J.E.; Mattoso, L.H.C. Advances in Functional Polymer Nanofibers: From Spinning Fabrication Techniques to Recent Biomedical Applications. ACS Appl. Mater. Interfaces 2020, 12, 45673-45701.

23. Hu, X.; Liu, S.; Zhou, G.; Huang, Y.; Xie, Z.; Jing, X. Electrospinning of polymeric nanofibers for drug delivery applications. J. Control. Release 2014, 185, 12-21.

24. Agarwal, S.; Wendorff, J.H.; Greiner, A. Progress in the field of electrospinning for tissue engineering applications. Adv. Mater. 2009, 21, 3343-3351.

25. Frenot, A.; Chronakis, I.S. Polymer nanofibers assembled by electrospinning. Curr. Opin. Colloid Interface Sci. 2003, 8, 64-75.

26. Oh, J.K.; Lee, D.I.; Park, J.M. Biopolymer-based microgels/nanogels for drug delivery applications. Prog. Polym. Sci. 2009, 34, 1261-1282.

27. Oh, J.K.; Drumright, R.; Siegwart, D.J.; Matyjaszewski, K. The development of microgels/nanogels for drug delivery applications. Prog. Polym. Sci. 2008, 33, 448-477.

28. Chew, S.; Wen, Y.; Dzenis, Y.; Leong, K. The Role of Electrospinning in the Emerging Field of Nanomedicine. Curr. Pharm. Des. 2006, 12, 4751-4770. 
29. Amidon, G.L.; Lennernäs, H.; Shah, V.P.; Crison, J.R. A Theoretical Basis for a Biopharmaceutic Drug Classification: The Correlation of in Vitro Drug Product Dissolution and in Vivo Bioavailability. Pharm. Res. An Off. J. Am. Assoc. Pharm. Sci. 1995, 12, 413-420.

30. Gita Chaurasia A Review on Pharmaceutical Preformulation Studies in Formulation and Development of New Drug Molecules. Int. J. Pharm. Sci. andResearch 2016, 6, 2313-2320.

31. Charoo, N.A. Critical Excipient Attributes Relevant to Solid Dosage Formulation Manufacturing. J. Pharm. Innov. 2020, 15, 163-181.

32. Jones, T.M. CHAPTER 1: Preformulation Studies. In RSC Drug Discovery Series; Royal Society of Chemistry, 2018; Vol. 2018-Janua, pp. 1-20.

33. Gupta, D.; Bhatia, D.; Dave, V.; Sutariya, V.; Varghese Gupta, S. Salts of Therapeutic Agents: Chemical, Physicochemical, and Biological Considerations. Molecules 2018, 23, 1719.

34. Patel, M.S.N.; Ahmed, M.H.; Saqib, M.; Shaikh, S.N. Chemical Modification: A unique solutions to Solubility problem. J. Drug Deliv. Ther. 2019, 9, 542-546.

35. Williams, G.R.; Chatterton, N.P.; Nazir, T.; Yu, D.G.; Zhu, L.M.; Branford-White, C.J. Electrospun nanofibers in drug delivery: Recent developments and perspectives. Ther. Deliv. 2012, 3, 515-533.

36. Ainurofiq, A.; Esther Dinda, K.; Widia Pangestika, M.; Himawati, U.; Dyah Wardhani, W.; Tamarin Sipahutar, Y. The effect of polymorphism on active pharmaceutical ingredients: A review. Int. J. Res. Pharm. Sci. 2020, 11, 1621-1630.

37. Nicoud, L.; Licordari, F.; Myerson, A.S. Estimation of the Solubility of Metastable Polymorphs: A Critical Review. Cryst. Growth Des. 2018, 18, 7228-7237.

38. Kalepu, S.; Nekkanti, V. Improved delivery of poorly soluble compounds using nanoparticle technology: a review. Drug Deliv. Transl. Res. 2016, 6, 319-332.

39. Jacob, S.; Nair, A.B.; Shah, J. Emerging role of nanosuspensions in drug delivery systems. Biomater. Res. 2020, 24, 3.

40. Zhang, X.; Xing, H.; Zhao, Y.; Ma, Z. Pharmaceutical dispersion techniques for dissolution and bioavailability enhancement of poorly water-soluble drugs. Pharmaceutics 2018, 10.

41. Gigliobianco, M.R.; Casadidio, C.; Censi, R.; Di Martino, P. Nanocrystals of poorly soluble drugs: Drug bioavailability and physicochemical stability. Pharmaceutics 2018, 10.

42. Nayak, A.K.; Panigrahi, P.P. Solubility Enhancement of Etoricoxib by Cosolvency Approach. ISRN Phys. Chem. 2012, 2012, 1-5.

43. Savjani, K.T.; Gajjar, A.K.; Savjani, J.K. Drug Solubility: Importance and Enhancement Techniques. ISRN Pharm. 2012, 2012, 1-10.

44. Kalepu, S.; Nekkanti, V. Insoluble drug delivery strategies: Review of recent advances and business prospects. Acta Pharm. Sin. B 2015, 5, 442-453.

45. Bozzuto, G.; Molinari, A. Liposomes as nanomedical devices. Int. J. Nanomedicine 2015, 10, 975-999.

46. Campolo, O.; Giunti, G.; Laigle, M.; Michel, T.; Palmeri, V. Essential oil-based nano-emulsions: Effect of different surfactants, sonication and plant species on physicochemical characteristics. Ind. Crops Prod. 2020, 157, 112935.

47. Akbarzadeh, A.; Rezaei-Sadabady, R.; Davaran, S.; Joo, S.W.; Zarghami, N.; Hanifehpour, Y.; Samiei, M.; Kouhi, M.; Nejati-Koshki, K. Liposome: Classification, preparation, and applications. Nanoscale Res. Lett. 2013, 8, 102.

48. Patel, M.S.N.; Ahmed, M.H.; Saqib, M.; Shaikh, S.N. Chemical Modification: A unique solutions to Solubility problem. J. Drug Deliv. Ther. 2019, 9, 542-546.

49. Martin, J.; Díaz-Montaña, E.J.; Asuero, A.G. Cyclodextrins: Past and Present. In Cyclodextrin - A Versatile Ingredient; InTech, 2018.

50. Di Cagno, M.P. The potential of cyclodextrins as novel active pharmaceutical ingredients: A short overview. Molecules 2017, 22.

51. Wang, X.; Zhang, L.; Ma, D.; Tang, X.; Zhang, Y.; Yin, T.; Gou, J.; Wang, Y.; He, H. Characterizing and Exploring the Differences in Dissolution and Stability Between Crystalline Solid Dispersion and Amorphous Solid Dispersion. AAPS PharmSciTech 2020, 21, 1-15.

52. Pandi, P.; Bulusu, R.; Kommineni, N.; Khan, W.; Singh, M. Amorphous solid dispersions: An update for preparation, characterization, mechanism on bioavailability, stability, regulatory considerations and marketed products. Int. J. Pharm. 2020, 586, 119560. 
53. Yazdanbakhsh, A.R.; Eslami, A.; Massoudinejad, M.; Avazpour, M. Enhanced degradation of sulfamethoxazole antibiotic from aqueous solution using Mn-WO3/LED photocatalytic process: Kinetic, mechanism, degradation pathway and toxicity reduction. Chem. Eng. J. 2020, 380, 122497.

54. Abdelkader, A.; Fathi, H.A.; Hamad, M.A.; Elsabahy, M. Nanomedicine: a new paradigm to overcome drug incompatibilities. J. Pharm. Pharmacol. 2020, 72, jphp.13292.

55. Akhtar, A.; Andleeb, A.; Waris, T.S.; Bazzar, M.; Moradi, A.-R.; Awan, N.R.; Yar, M. Neurodegenerative diseases and effective drug delivery: A review of challenges and novel therapeutics. J. Control. Release 2020.

56. Bae, Y.H.; Park, K. Targeted drug delivery to tumors: Myths, reality and possibility. J. Control. Release 2011, 153, 198-205.

57. Grumezescu, A.M. Design of nanostructures for theranostics applications; Elsevier, 2018; ISBN 9780128136690.

58. Jin, K.T.; Lu, Z.B.; Chen, J.Y.; Liu, Y.Y.; Lan, H.R.; Dong, H.Y.; Yang, F.; Zhao, Y.Y.; Chen, X.Y. Recent Trends in Nanocarrier-Based Targeted Chemotherapy: Selective Delivery of Anticancer Drugs for Effective Lung, Colon, Cervical, and Breast Cancer Treatment. J. Nanomater. 2020, 2020.

59. He, F.; Wen, N.; Xiao, D.; Yan, J.; Xiong, H.; Cai, S.; Liu, Z.; Liu, Y. Aptamer-Based Targeted Drug Delivery Systems: Current Potential and Challenges. Curr. Med. Chem. 2018, 27, 2189-2219.

60. Tekade, R.K. Basic fundamentals of drug delivery; Elsevier, 2018; ISBN 9780128179093.

61. Pattni, B.S.; Torchilin, V.P. Targeted Drug Delivery Systems: Strategies and Challenges. In; Springer, Cham, 2015; pp. 3-38.

62. Hsu, M.Y.; Huang, Y.T.; Weng, C.J.; Chen, C.M.; Su, Y.F.; Chu, S.Y.; Tseng, J.H.; Wu, R.C.; Liu, S.J. Preparation and in vitro/in vivo evaluation of doxorubicin-loaded poly[lactic-co-glycol acid] microspheres using electrospray method for sustained drug delivery and potential intratumoral injection. Colloids Surfaces B Biointerfaces 2020, 190, 110937.

63. Liu, D.; Liu, S.; Jing, X.; Li, X.; Li, W.; Huang, Y. Necrosis of cervical carcinoma by dichloroacetate released from electrospun polylactide mats. Biomaterials 2012, 33, 4362-4369.

64. Ramírez-Agudelo, R.; Scheuermann, K.; Gala-García, A.; Monteiro, A.P.F.; Pinzón-García, A.D.; Cortés, M.E.; Sinisterra, R.D. Hybrid nanofibers based on poly-caprolactone/gelatin/hydroxyapatite nanoparticlesloaded Doxycycline: Effective anti-tumoral and antibacterial activity. Mater. Sci. Eng. C 2018, 83, $25-34$.

65. Ramier, J.; Bouderlique, T.; Stoilova, O.; Manolova, N.; Rashkov, I.; Langlois, V.; Renard, E.; Albanese, P.; Grande, D. Biocomposite scaffolds based on electrospun poly(3-hydroxybutyrate) nanofibers and electrosprayed hydroxyapatite nanoparticles for bone tissue engineering applications. Mater. Sci. Eng. C 2014, 38, 161-169.

66. Li, J.; Xu, W.; Li, D.; Liu, T.; Zhang, Y.S.; Ding, J.; Chen, X. Locally Deployable Nanofiber Patch for Sequential Drug Delivery in Treatment of Primary and Advanced Orthotopic Hepatomas. ACS Nano 2018, $12,6685-6699$.

67. Mai, Z.; Chen, J.; He, T.; Hu, Y.; Dong, X.; Zhang, H.; Huang, W.; Ko, F.; Zhou, W. Electrospray biodegradable microcapsules loaded with curcumin for drug delivery systems with high bioactivity + . RSC Adv. 2017, 7, 1724-1734.

68. Yuan, Y.; Choi, K.; Choi, S.O.; Kim, J. Early stage release control of an anticancer drug by drug-polymer miscibility in a hydrophobic fiber-based drug delivery system. RSC Adv. 2018, 8, 19791-19803.

69. Bonadies, I.; Maglione, L.; Ambrogi, V.; Paccez, J.D.; Zerbini, L.F.; Rocha e Silva, L.F.; Picanço, N.S.; Tadei, W.P.; Grafova, I.; Grafov, A.; et al. Electrospun core/shell nanofibers as designed devices for efficient Artemisinin delivery. Eur. Polym. J. 2017, 89, 211-220.

70. Che, H.L.; Lee, H.J.; Uto, K.; Ebara, M.; Kim, W.J.; Aoyagi, T.; Park, I.K. Simultaneous drug and gene delivery from the biodegradable poly( $\varepsilon$-caprolactone) nanofibers for the treatment of liver cancer. $J$. Nanosci. Nanotechnol. 2015, 15, 7971-7975.

71. Li, P.; Xu, J.; Qi, B.; Li, K.; Gu, X.; Niu, X.; Fan, Y. One-Step Preparation of Poly(Lactide-Co-Glycolide) Fiber Rods Embedding with Luminescent Materials as a Drug Delivery System via Electrospray. Nanosci. Nanotechnol. Lett. 2018, 10, 1287-1291.

72. Reddy, A.S.; Lakshmi, B.A.; Kim, S.; Kim, J. Synthesis and characterization of acetyl curcumin-loaded core/shell liposome nanoparticles via an electrospray process for drug delivery, and theranostic applications. Eur. J. Pharm. Biopharm. 2019, 142, 518-530.

73. Ma, L.; Yang, G.; Wang, N.; Zhang, P.; Guo, F.; Meng, J.; Zhang, F.; Hu, Z.; Wang, S.; Zhao, Y. Trap effect of three-dimensional fibers network for high efficient cancer-cell capture. Adv. Healthc. Mater. 2015, 4, 838843. 
74. Wang, B.; Li, H.; Yao, Q.; Zhang, Y.; Zhu, X.; Xia, T.; Wang, J.; Li, G.; Li, X.; Ni, S. Local in vitro delivery of rapamycin from electrospun PEO/PDLLA nanofibers for glioblastoma treatment. Biomed. Pharmacother. 2016, 83, 1345-1352.

75. Chatterjee, M.; Maity, R.; Das, S.; Mahata, N.; Basu, B.; Chanda, N. Electrospray-based synthesis of fluorescent poly ( d , 1 -lactide- co -glycolide) nanoparticles for the efficient delivery of an anticancer drug and self-monitoring its effect in drug-resistant breast cancer cells. Mater. Adv. 2020.

76. Ghaffarzadegan, R.; Khoee, S.; Rezazadeh, S. Fabrication, characterization and optimization of berberineloaded PLA nanoparticles using coaxial electrospray for sustained drug release. DARU, J. Pharm. Sci. 2020, 28, 237-252.

77. Potrč, T.; Baumgartner, S.; Roškar, R.; Planinšek, O.; Lavrič, Z.; Kristl, J.; Kocbek, P. Electrospun polycaprolactone nanofibers as a potential oromucosal delivery system for poorly water-soluble drugs. Eur. J. Pharm. Sci. 2015, 75, 101-113.

78. Canbolat, M.F.; Celebioglu, A.; Uyar, T. Drug delivery system based on cyclodextrin-naproxen inclusion complex incorporated in electrospun polycaprolactone nanofibers. Colloids Surfaces B Biointerfaces 2014, 115, 15-21.

79. Lu, H.; Wang, Q.; Li, G.; Qiu, Y.; Wei, Q. Electrospun water-stable zein/ethyl cellulose composite nanofiber and its drug release properties. Mater. Sci. Eng. C 2017, 74, 86-93.

80. Adeli-Sardou, M.; Yaghoobi, M.M.; Torkzadeh-Mahani, M.; Dodel, M. Controlled release of lawsone from polycaprolactone/gelatin electrospun nano fibers for skin tissue regeneration. Int. J. Biol. Macromol. 2019, 124, 478-491.

81. Castillo-Ortega, M.M.; Montaño-Figueroa, A.G.; Rodríguez-Félix, D.E.; Munive, G.T.; Herrera-Franco, P.J. Amoxicillin embedded in cellulose acetate-poly (vinyl pyrrolidone) fibers prepared by coaxial electrospinning: Preparation and characterization. Mater. Lett. 2012, 76, 250-254.

82. Yang, G.; Wang, J.; Li, L.; Ding, S.; Zhou, S. Electrospun micelles/drug-loaded nanofibers for timeprogrammed multi-agent release. Macromol. Biosci. 2014, 14, 965-976.

83. Zupančič, Š.; Preem, L.; Kristl, J.; Putrinš, M.; Tenson, T.; Kocbek, P.; Kogermann, K. Impact of PCL nanofiber mat structural properties on hydrophilic drug release and antibacterial activity on periodontal pathogens. Eur. J. Pharm. Sci. 2018, 122, 347-358.

84. Chen, S.; Ge, L.; Mueller, A.; Carlson, M.A.; Teusink, M.J.; Shuler, F.D.; Xie, J. Twisting electrospun nanofiber fine strips into functional sutures for sustained co-delivery of gentamicin and silver. Nanomedicine Nanotechnology, Biol. Med. 2017, 13, 1435-1445.

85. de Cassan, D.; Sydow, S.; Schmidt, N.; Behrens, P.; Roger, Y.; Hoffmann, A.; Hoheisel, A.L.; Glasmacher, B.; Hänsch, R.; Menzel, H. Attachment of nanoparticulate drug-release systems on poly( $\varepsilon$-caprolactone) nanofibers via a graftpolymer as interlayer. Colloids Surfaces B Biointerfaces 2018, 163, 309-320.

86. Han, D.; Sherman, S.; Filocamo, S.; Steckl, A.J. Long-term antimicrobial effect of nisin released from electrospun triaxial fiber membranes. Acta Biomater. 2017, 53, 242-249.

87. Wright, M.E.; Parrag, I.C.; Yang, M.; Santerre, J.P. Electrospun polyurethane nanofiber scaffolds with ciprofloxacin oligomer versus free ciprofloxacin: Effect on drug release and cell attachment. J. Control. Release 2017, 250, 107-115.

88. Martínez-Ortega, L.; Mira, A.; Fernandez-Carvajal, A.; Reyes Mateo, C.; Mallavia, R.; Falco, A. Development of a new delivery system based on drug-loadable electrospun nanofibers for psoriasis treatment. Pharmaceutics 2019, 11.

89. Haider, A.; Gupta, K.C.; Kang, I.K. Morphological effects of HA on the cell compatibility of electrospun HA/PLGA composite nanofiber scaffolds. Biomed Res. Int. 2014, 2014.

90. Lancina, M.G.; Shankar, R.K.; Yang, H. Chitosan nanofibers for transbuccal insulin delivery. J. Biomed. Mater. Res. - Part A 2017, 105, 1252-1259.

91. Chen, J.; Pan, H.; Yang, Y.; Xiong, S.; Duan, H.; Yang, X.; Pan, W. Self-assembled liposome from multilayered fibrous mucoadhesive membrane for buccal delivery of drugs having high first-pass metabolism. Int. J. Pharm. 2018, 547, 303-314.

92. Rasekh, M.; Ahmad, Z.; Cross, R.; Hernández-Gil, J.; Wilton-Ely, J.D.E.T.; Miller, P.W. Facile Preparation of Drug-Loaded Tristearin Encapsulated Superparamagnetic Iron Oxide Nanoparticles Using Coaxial Electrospray Processing. Mol. Pharm. 2017, 14, 2010-2023.

93. Patil, S.; Mahadik, A.; Nalawade, P.; More, P. Crystal engineering of lactose using electrospray technology: carrier for pulmonary drug delivery. Drug Dev. Ind. Pharm. 2017, 43, 2085-2091. 
94. Ma, Y.; Björnmalm, M.; Wise, A.K.; Cortez-Jugo, C.; Revalor, E.; Ju, Y.; Feeney, O.M.; Richardson, R.T.; Hanssen, E.; Shepherd, R.K.; et al. Gel-Mediated Electrospray Assembly of Silica Supraparticles for Sustained Drug Delivery. ACS Appl. Mater. Interfaces 2018, 10, 31019-31031.

95. Rehman, A.; Jafari, S.M.; Tong, Q.; Riaz, T.; Assadpour, E.; Aadil, R.M.; Niazi, S.; Khan, I.M.; Shehzad, Q.; Ali, A.; et al. Drug nanodelivery systems based on natural polysaccharides against different diseases. Adv. Colloid Interface Sci. 2020, 284, 102251.

96. Raghavan, P.; Lim, D.H.; Ahn, J.H.; Nah, C.; Sherrington, D.C.; Ryu, H.S.; Ahn, H.J. Electrospun polymer nanofibers: The booming cutting edge technology. React. Funct. Polym. 2012, 72, 915-930.

97. George, G.; Senthil, T.; Luo, Z.; Anandhan, S. Sol-gel electrospinning of diverse ceramic nanofibers and their potential applications. In Electrospun Polymers and Composites; Elsevier, 2021; pp. 689-764.

98. Dias, J.R.; Alves, A.I.F.; Marzia-Ferreira, C.A.; Alves, N.M. Electrospinning Fabrication Strategies. In Electrospun Materials and Their Allied Applications; Wiley, 2020; pp. 1-52.

99. Cheng, J.; Jun, Y.; Qin, J.; Lee, S.H. Electrospinning versus microfluidic spinning of functional fibers for biomedical applications. Biomaterials 2017, 114, 121-143.

100. Du, X.Y.; Li, Q.; Wu, G.; Chen, S. Multifunctional Micro/Nanoscale Fibers Based on Microfluidic Spinning Technology. Adv. Mater. 2019, 31, 1903733.

101. Chen, C.; Dirican, M.; Zhang, X. Centrifugal spinning-High rate production of nanofibers. In Electrospinning: Nanofabrication and Applications; Elsevier, 2018; pp. 321-338 ISBN 9780323512701.

102. Vasireddi, R.; Kruse, J.; Vakili, M.; Kulkarni, S.; Keller, T.F.; Monteiro, D.C.F.; Trebbin, M. Solution blow spinning of polymer/nanocomposite micro-/nanofibers with tunable diameters and morphologies using a gas dynamic virtual nozzle. Sci. Rep. 2019, 9.

103. Cornejo Bravo, J.M.; Villarreal Gómez, L.J.; Serrano Medina, A. Electrospinning for Drug Delivery Systems: Drug Incorporation Techniques. In Electrospinning - Material, Techniques, and Biomedical Applications; InTech, 2016.

104. Khalf, A.; Madihally, S. V. Recent advances in multiaxial electrospinning for drug delivery. Eur. J. Pharm. Biopharm. 2017, 112, 1-17.

105. Ghosal, K.; Agatemor, C.; Tucker, N.; Kny, E.; Thomas, S. CHAPTER 1: Electrical Spinning to Electrospinning: A Brief History. In RSC Soft Matter; Royal Society of Chemistry, 2018; Vol. 2018-Janua, pp. 1-23 ISBN 9781788011006.

106. Figen, A.K. History, Basics, and Parameters of Electrospinning Technique. In Electrospun Materials and Their Allied Applications; Wiley, 2020; pp. 53-69.

107. Long, Y.Z.; Yan, X.; Wang, X.X.; Zhang, J.; Yu, M. Electrospinning. In Electrospinning: Nanofabrication and Applications; Elsevier, 2018; pp. 21-52 ISBN 9780323512701.

108. Pant, B.; Park, M.; Park, S.J. Drug delivery applications of core-sheath nanofibers prepared by coaxial electrospinning: A review. Pharmaceutics 2019, 11, 305.

109. Li, Z.; Mei, S.; Dong, Y.; She, F.; Li, Y.; Li, P.; Kong, L. Functional nanofibrous biomaterials of tailored structures for drug delivery - a critical review. Pharmaceutics 2020, 12, 1-23.

110. Buzgo, M.; Mickova, A.; Rampichova, M.; Doupnik, M. Blend electrospinning, coaxial electrospinning, and emulsion electrospinning techniques. In Core-Shell Nanostructures for Drug Delivery and Theranostics; Elsevier, 2018; pp. 325-347.

111. Wang, K.; Wang, P.; Wang, M.; Yu, D.G.; Wan, F.; Bligh, S.W.A. Comparative study of electrospun crystalbased and composite-based drug nano depots. Mater. Sci. Eng. C 2020, 113, 110988.

112. Lian, H.; Meng, Z. Melt electrospinning vs. solution electrospinning: A comparative study of drug-loaded poly (E-caprolactone) fibres. Mater. Sci. Eng. C 2017, 74, 117-123.

113. Nikmaram, N.; Roohinejad, S.; Hashemi, S.; Koubaa, M.; Barba, F.J.; Abbaspourrad, A.; Greiner, R. Emulsion-based systems for fabrication of electrospun nanofibers: Food, pharmaceutical and biomedical applications. RSC Adv. 2017, 7, 28951-28964.

114. Hu, J.; Prabhakaran, M.P.; Tian, L.; Ding, X.; Ramakrishna, S. Drug-loaded emulsion electrospun nanofibers: Characterization, drug release and in vitro biocompatibility. RSC Adv. 2015, 5, 100256-100267.

115. Duque Sánchez, L.; Brack, N.; Postma, A.; Pigram, P.J.; Meagher, L. Surface modification of electrospun fibres for biomedical applications: A focus on radical polymerization methods. Biomaterials 2016, 106, 2445. 
116. Das, P.; Ojah, N.; Kandimalla, R.; Mohan, K.; Gogoi, D.; Dolui, S.K.; Choudhury, A.J. Surface modification of electrospun PVA/chitosan nanofibers by dielectric barrier discharge plasma at atmospheric pressure and studies of their mechanical properties and biocompatibility. Int. J. Biol. Macromol. 2018, 114, 1026-1032.

117. Ojah, N.; Borah, R.; Ahmed, G.A.; Mandal, M.; Choudhury, A.J. Surface modification of electrospun silk/AMOX/PVA nanofibers by dielectric barrier discharge plasma: physiochemical properties, drug delivery and in-vitro biocompatibility. Prog. Biomater. 2020, 1-19.

118. Yu, D.G.; Li, J.J.; Zhang, M.; Williams, G.R. High-quality Janus nanofibers prepared using three-fluid electrospinning. Chem. Commun. 2017, 53, 4542-4545.

119. Yu, D.G.; Yang, C.; Jin, M.; Williams, G.R.; Zou, H.; Wang, X.; Annie Bligh, S.W. Medicated Janus fibers fabricated using a Teflon-coated side-by-side spinneret. Colloids Surfaces B Biointerfaces 2016, 138, 110-116.

120. Zheng, J.; Zhou, C.; Zhang, Z.; Pan, Y.; Kang, G.; Jiang, J.; Liu, J.; Zheng, G. Highly efficient air-assisted multi-jet electrospinning with curved arranged spinnerets. AIP Adv. 2020, 10, 025307.

121. El-Sayed, H.; Vineis, C.; Varesano, A.; Mowafi, S.; Andrea Carletto, R.; Tonetti, C.; Abou Taleb, M. A critique on multi-jet electrospinning: State of the art and future outlook. Nanotechnol. Rev. 2019, 8, 236-245.

122. Bhattarai, R.S.; Bachu, R.D.; Boddu, S.H.S.; Bhaduri, S. Biomedical applications of electrospun nanofibers: Drug and nanoparticle delivery. Pharmaceutics 2019, 11, 5.

123. Khalf, A.; Madihally, S. V. Modeling the permeability of multiaxial electrospun poly( $\varepsilon$-caprolactone)gelatin hybrid fibers for controlled doxycycline release. Mater. Sci. Eng. C 2017, 76, 161-170.

124. de Mohac, L.M.; Keating, A.V.; Pina, M. de F.; Raimi-Abraham, B.T. Engineering of nanofibrous amorphous and crystalline solid dispersions for oral drug delivery. Pharmaceutics 2019, 11, 7.

125. Wu, J.; Zhang, Z.; Gu, J.; Zhou, W.; Liang, X.; Zhou, G.; Han, C.C.; Xu, S.; Liu, Y. Mechanism of a long-term controlled drug release system based on simple blended electrospun fibers. J. Control. Release 2020, 320, 337-346.

126. Amarjargal, A.; Brunelli, M.; Fortunato, G.; Spano, F.; Kim, C.S.; Rossi, R.M. On-demand drug release from tailored blended electrospun nanofibers. J. Drug Deliv. Sci. Technol. 2019, 52, 8-14.

(C) 2020 by the authors. Submitted for possible open access publication under the terms and conditions of the Creative Commons Attribution (CC BY) license (http://creativecommons.org/licenses/by/4.0/). 